HID 44 (2017)

\title{
EL MAESTRAZGO DE ALFONSO MÉNDEZ DE GUZMÁN EN LA ORDEN DE SANTIAGO (1338-1342)
}

\author{
THE GRAND MASTERSHIP OF ALFONSO MÉNDEZ DE GUZMÁN IN \\ THE ORDER OF SANTIAGO (1338-1342)
}

\section{MANUEl LóPEZ FERNÁNDEZ}

UNED, Centro Asociado de Algeciras

lopezfernandezm75@gmail.com

RESUMEN: Alfonso Méndez de Guzmán fue nombrado maestre de la Orden de Santiago como consecuencia de la injerencia de Alfonso XI en los asuntos internos de los santiaguistas. El tiempo que Méndez de Guzmán permaneció al frente de la Orden fue corto, pero muy intenso al coincidir su gobierno con la ofensiva de los benimerines y la contraofensiva de Alfonso XI que siguió a la batalla del Salado. Pero no sólo tratamos aquí de la actuación del maestre en estos hechos de armas, sino que seguimos su labor administrativa al tiempo de dar a conocer sus colaboradores más cercanos y también su itinerario. Para ello nos hemos apoyado en las crónicas reales y en la documentación, entresacando de ésta el interesante documento que aportamos en el apéndice documental.

Palabras ClaVes: Orden de Santiago; Alfonso Méndez de Guzmán; Alfonso XI; Leonor de Guzmán; Siglo XIV.

AbSTRACT: Alfonso Méndez de Guzmán became Grand Master of the Order of Santiago through the imposition of Alfonso XI, at a time when the king sought to place people of his entire confidence at the head of the military orders. Méndez de Guzmán responded in great measure to the expectations that the King of Castile had placed in him. He took part in the battle of Salado and in the conquest of Alcalá la Real. However, we deal here not only with the military activity of the Grand Master but also his work as administrator at the head of the order. We include a list of the names of his closest collaborators and details of his itinerary. For this we have studied the royal chronicles and documents and in the index we include a particularly interesting document.

KeYwords: Order of Santiago; Alfonso Méndez de Guzmán; Alfonso XI; Leonor de Guzmán; $14^{\text {th }}$ century. 


\section{ACERCAMiEnto AL TEMA}

La llegada de Alfonso Méndez de Guzmán al maestrazgo ${ }^{1}$ de la Orden de Santiago fue consecuencia clara y directa de la injerencia de Alfonso XI en los asuntos internos de los santiaguistas. El rey parecía decidido por entonces a colocar al frente de las órdenes militares a hombres de su entera confianza ${ }^{2}$, después de los conflictos nobiliarios que había tenido con determinados señores, especialmente con don Juan Núñez de Lara y con don Juan Manuel, a quienes acababa de atraer a su lado gracias a la mediación de doña Juana de Lara "la Palomilla", madre de don Juan Núñez, en junio de $1338^{3}$.

El nombramiento de Méndez de Guzmán como maestre de la Orden de Santiago, hecho en agosto de 1338 según veremos, guarda cierto paralelismo con la anterior designación de Gonzalo Martínez de Oviedo al frente de la Orden de Alcántara, efectuada en mayo de 1337. Lo irónico de la situación, digna de resaltar aquí, es que Martínez de Oviedo se mostrara crítico con el nombramiento de Méndez de Guzmán como maestre de Santiago, postura ésta que distorsionó la carrera política del maestre alcantarino hasta llevarle al enfrentamiento con el rey de Castilla, quien finalmente ordenó su muerte al sentirse traicionado por un hombre de su entera confianza.

Martínez de Oviedo era un oficial de la cámara de Alfonso XI, despensero mayor según la Crónica de Alfonso $\mathrm{XI}^{4}$, cuando fue nombrado maestre de Alcántara; por su parte, Alfonso Méndez de Guzmán era algo más que el camarero mayor del monarca en el momento de su nombramiento, tal y como veremos en su momento. Por lo pronto, diremos ahora que nuestro hombre es citado en la Crónica por primera vez con ocasión de la coronación de Alfonso XI en Burgos, en agosto de 1332, figurando entre el reducido grupo de los ricoshombres del reino que fueron elegidos para ingresar como caballeros de la Orden de la Banda ${ }^{5}$, fundada precisamente por el mismo monarca.

Alfonso Méndez de Guzmán pertenecía al linaje de la familia Guzmán afincada en Sevilla, pues era hijo de Pedro Núñez de Guzmán y de Juana Ponce de León. El padre del que llegaría a ser maestre de la Orden de Santiago era sobrino por línea paterna de Alonso Pérez de Guzmán "el Bueno", y pariente cercano de

1. Empleamos este término para referirnos a la labor de gobierno de la dignidad maestral, siguiendo los pasos de Lomax 1965, p.13 y de Ayala Martínez 2003; como la utilización de dicho término por parte de este último autor resulta abundante y variada, remitimos al índice de la obra.

2. Entrar en detalles para explicar antecedentes y consecuencias de la injerencia de los reyes de Castilla en las órdenes militares desbordaría el espacio asignado para este artículo, distorsionando el contenido del mismo por otra parte. A quien desea profundizar en estos aspectos lo remitimos a la obra de Ayala Martínez, 2003, pp. 709-716.

3. Este asunto se puede ver con cierto detalle en Sánchez Arcilla-Bernal 1995, p. 207. También en Arias Guillén 2012, pp. 202 y ss.

4. Nos referimos a Corónica del muy alto et muy católico rey don Alfonso el onceno. En adelante nos referiremos a ella simplemente como Crónica.

5. Ibidem, p. 235. 
Alvar Pérez de Guzmán ${ }^{6}$, mientras que por línea materna descendía de un antiguo adelantado de la Frontera, Fernán Pérez Ponce ${ }^{7}$.

No hay duda, pues, de que a la altura de 1332 Alfonso Méndez estaba bien situado entre la aristocracia del reino, y posiblemente gozara de aptitudes personales que le permitieran promocionar dentro de su entorno social, pero en este sentido no podemos obviar que, desde 1327, se había dado otra circunstancia ajena a su persona y que vendría a favorecerle en su carrera. Esta circunstancia no fue otra que el rey de Castilla se había enamorado de su hermana, Leonor de Guzmán ${ }^{8}$, con la que mantenía una relación estable desde 1330 hasta el punto de darle el primer hijo al monarca, Pedro de Aguilar, nacido a finales de 1331 o primeros días del año siguiente ${ }^{9}$.

Es posible que Alfonso Méndez ya hubiese destacado militarmente en las campañas que Alfonso XI realizó contra los musulmanes de Granada desde el año 1327, pero sospechamos que la relación entre su hermana y el rey pudo ser decisiva a la hora de buscarle esposa, pues nuestro personaje vino a casarse con doña María de la Cerda $^{10}$-hija de uno de los descendientes del infante Fernando de la Cerda ${ }^{11} \mathrm{y}$, por tanto, familiar relativamente cercano al rey de Castilla-, matrimonio del que no nacieron hijos según consta documentalmente ${ }^{12}$.

Con estos atributos, no sorprende tanto que Alfonso Méndez de Guzmán fuese un personaje muy cercano a la figura del monarca castellano, ni que éste le nombrara su camarero mayor. Desde luego, con tal título figura nuestro hombre en un documento $^{13}$ extendido en Alcalá de Henares en el que Alfonso XI comunica al concejo de Sevilla que había otorgado a Alfonso Méndez de Guzmán el señorío de Huelva ${ }^{14}$, perteneciente al concejo sevillano, razón por la que la Corona hubo de desprenderse previamente de Arcos de la Frontera y canjearlo al concejo de

6. Sánchez Saus 1991, p. 110.

7. Sánchez Saus 1989, pp. 346.

8. Algunos aspectos de las relaciones de esta señora con el rey de Castilla han sido tratados en una recientemente publicación de la Universidad de Sevilla; autores y trabajos han sido coordinados por el profesor Manuel García Fernández. Véase así en VV. AA. 2012.

9. González Crespo 1988, pp. 289-303. Conviene señalar que el infante don Fernando, primer hijo de la reina doña María y heredero del trono, nació en 1332 pero murió al año siguiente.

10. En el Memorial del duque de Medinaceli a Felipe V, escrito por don Luis de Salazar, en 1707, compuesto y trascrito por Juan Luis Pérez Arribas en 1707, f. 45, se lee: "Doña María de la Cerda que yace en San Francisco de Villafranca de Varcárcel (sic), y se cree que llevó en dote aquella villa cuando casó con don Alfonso Méndez de Guzmán, Rico hombre, y después Maestre de Santiago, no tuvieron hijos como parece en el testamento de doña Inés su hermana, que confiesa haber sido heredera de doña María".

11. Concretamente de don Alfonso de la Cerda. Por tanto, debemos suponer que el matrimonio hubo de celebrase después de la primavera de 1331, cuando Alfonso de la Cerda reconoce a Alfonso $\mathrm{XI}$ como verdadero heredero del trono de Castilla.

12. Al parecer tuvo un hijo bastardo llamado como el padre del maestre, Pedro Núñez de Guzmán, con quien se extingue esta línea de los Guzmán. En esto seguimos Sánchez Saus, 1991, p. 111.

13. Archivo Municipal de Sevilla. Sección 1, carpeta $2^{\mathrm{a}}$ de Privilegios, documento $n^{\circ} 44$.

14. Tal circunstancia la recoge Ladero Quesada 1998, pp. 97-141. Este autor señala que el señorío de Huelva fue compartido entre el maestre y su hermana Leonor de Guzmán, pero en el documento citado en la nota anterior para nada se menciona a esta última. 
Sevilla por el señorío onubense. En el documento extendido en Alcalá de Henares y dirigido al concejo de Arcos para comunicarle que pasaba de realengo al concejo de Sevilla -como consecuencia del cambio por Huelva-, el monarca se refiere a Alfonso Méndez como "nuestro camarero mayor" en una fecha -17 de octubre de 1338-, en la que nuestro hombre ya tenía que ser maestre de la Orden de Santiago, aunque desconocemos los motivo por los cuales el rey omite este título. De modo que si don Alfonso Méndez era el camarero mayor de Alfonso XI en el mes de octubre, es muy probable que ya lo fuese con antelación a la llegada del rey a la ciudad de Cuenca, lugar donde el monarca castellano tuvo noticias de la muerte del hasta entonces maestre santiaguista, Vasco Rodríguez de Cornado ${ }^{15}$.

\section{Los conflictos en la Orden de Santiago al morir Vasco RODRÍGUEZ}

Por lo que nos dicen los autores de la primera crónica de la Orden de Santiago $^{16}$, Pedro de Orozco y Juan de la Parra, el maestre Alfonso Méndez de Guzmán se pasó luchando con los moros los cuatro años de su maestrazgo, viniendo a resaltar su actuación en la batalla del Salado de Tarifa. Señalan dichos comendadores respecto al maestre Méndez de Guzmán que "este maestre gastaba su tiempo en prosecución de la guerra contra los dichos moros ynfieles segund era obligado". Tales circunstancias nos conducen a pensar en el reconocimiento de los comendadores santiaguistas hacia la labor del dirigente de la Orden, pero resulta llamativo que el comentario anterior lo continúen con la enigmática frase: "fasta pagar en ello la debda natural que devia”, concluyendo que el citado maestre fue el vigésimo cuarto que hubo en la Orden.

Para conocer a qué se refieren los comendadores con semejante frase se hace necesario seguir leyendo su historia, ya que en la misma se encuentra la respuesta a tal pregunta, pero no en el capítulo dedicado a Méndez de Guzmán, sino en el que hablan de don Álvaro de Luna, maestre que también fue elegido bajo el abierto favor del rey Juan II. En este caso nos encontramos con una larga cita en la que se dice ${ }^{17}$ :

"Pero es mucho admirar, a los que este estado de maestre, alcançar desean, que deven entrar por la puerta de la orden, con elección justa i canónicamente fecha, porque este señor maestre -se refieren don Álvaro de Luna- $i$ el dicho señor Ynfante -hablan del infante don Enrique de Aragón-, i don Juan García de Padilla, $i$ el Ynfante don Fadrique, hermano del Rey don Pedro, i don Gomez Suarez de Figueroa, i don Martin Barragan, i don Alonso Mendez, sus antecesores, que ovieron la dignidad maestral con mano i favor de los Reyes, fuera de la voluntad y libertad de la orden, todos murieron a fierro, i ovieron los dichos fines que dicho avemos.

15. Así se recoge en Crónica, p. 294.

16. De Orozco y De La Parra 1978, p. 375.

17. Ibidem, p. 389. 
De lo anterior sacamos en consecuencia que Alonso Méndez de Guzmán, ni los otros maestres que fueron elegidos con el favor real, gozaban de las simpatías de los primeros historiadores de la Orden ${ }^{18}$. Por tanto, no sorprende que los comendadores Orozco y de la Parra no se esforzaran mucho en detallar los hechos que llevaron a Méndez de Guzmán al maestrazgo santiaguista; porque en el archivo del convento de Uclés debía existir información sobre el asunto, pues Francisco de $\operatorname{Rades}^{19}$, aparte de apoyarse en las crónicas reales para informarnos de aquellos acontecimientos, incluyó algunos datos que hubo de sacar de los archivos de la Orden de Santiago.

Recomponiendo la situación relativa al nombramiento de Alfonso Méndez de Guzmán, diremos que las crónicas de Alfonso XI señalan al respecto que la corte estaba en Cuenca cuando el rey se enteró del fallecimiento del maestre Vasco Rodríguez, y que el monarca se apresuró en comunicar a los santiaguistas que no eligieran nuevo maestre sin contar con su parecer, por lo que debían realizar la elección en $\mathrm{Cuenca}^{20}$. Esta orden hubo de llegar a las máximas autoridades santiaguistas antes de la reunión del consejo elector ${ }^{21}$, pero -a pesar de la corta distancia entre Cuenca y Uclés- no parece que los electores de la Orden se dignaran en acercarse a la primera para escuchar la opinión real, sino que se reunieron en la segunda localidad ${ }^{22}$ alegando que sus estatutos no le permitían hacer la elección fuera de sus territorios. Aunque esto último podía ser relativamente convincente, el trasfondo de la cuestión estaba más allá del cumplimiento de los estatutos de la Orden, e invita a creer que las intenciones de las autoridades santiaguistas no estaban en plena sintonía con las del rey de Castilla.

Según relata Francisco de Rades, la asamblea reunida en Uclés eligió, pero no por unanimidad, como nuevo maestre al que hasta entonces había sido comendador mayor de Castilla, Vasco López ${ }^{23}$, hombre que había cometido con anterioridad algunas irregularidades que no gustaron al monarca castellano y de las que luego hablaremos; así que al enterarse Alfonso XI de aquella elección, hecha contra su voluntad, no se demoró en ordenar a priores y comendadores bajo graves penas -así lo precisa Rades- que no entregaran las villas y fortalezas santiaguistas

18. Esta opinión de los comendadores santiaguistas tal vez se deba a los desagradables acontecimientos vivido en la Orden en el siglo XV por el nombramiento de los maestres que precedieron a Alfonso de Cárdenas.

19. Rades y Andrada 1980, ff. 42v-45r.

20. Así consta en Gran Crónica de Alfonso XI. (En adelante nos referiremos a ella como Gran Crónica), 1976, p. 251.

21. Conviene precisar al respecto que no era necesario la celebración de un Capítulo General de la Orden para elegir nuevo maestre. Para tal fin sólo era necesario que se reuniera el consejo elector, compuesto por los trece de la Orden, además de los priores de los conventos de Uclés y san Marcos.

22. Rades y Andrada 1980, f. 43r.

23. Vasco Pérez era comendador mayor de Castilla en junio de 1333, según consta en un documento extendido en Alcalá de los Gazules cuando la Orden iba camino de Gibraltar para descercar a este castillo del sitio a que lo tenían sometido los benimerines. Cuatro años antes, en un documento de julio de 1329 era comendador de Segura de la Sierra, mientras Rodrigo Yáñez aparece como comendador mayor de Castilla. Véase esto último en Porras Arboledas 1997, documento 8. 
al nuevo maestre y que fuesen a Guadalajara, ciudad a la que ya se había trasladado el monarca ${ }^{24}$.

Vasco López, temiendo lo peor y haciendo caso omiso al requerimiento del rey, se alejó de Uclés y se fue a Montánchez; pero la mayor parte de los electores de la Orden acudieron a Guadalajara, donde les informó el monarca que quería el maestrazgo de la Orden para su hijo don Fadrique -un niño de cuatro años por entonces, hijo también de doña Leonor de Guzmán-, al tiempo de ordenarles que se reunieran de nuevo en Ocaña ${ }^{25}$ mientras él salía para Madrid. Ante esta postura, cabe sospechar que el rey esperara todavía atraerse al recién nombrado maestre, pero éste dejó la fortaleza de Montánchez y se fue para Portugal, por lo que pocos días después el nuevo comendador mayor de Castilla, Sancho Fernández ${ }^{26}$-Sancho Sánchez para nosotros-, se desplazó a Madrid con el fin de informar al rey que le esperaban en Ocaña para proceder a la elección del infante don Fadrique. Alfonso XI se desplazó de Madrid a Ocaña, pero no venía acompañado de su hijo don Fadrique como pudiera parecer lógico, sino de su camarero mayor, Alfonso Méndez de Guzmán, convencido ya ${ }^{27}$ que resultaría más positivo colocar al frente de la Orden a un hombre maduro y de su entera confianza que a un Infante de corta edad, circunstancia esta última que resultaba difícil de aceptar por parte de los santiaguistas.

Así que una vez reunido el Capítulo en presencia del rey de Castilla, y para dar formalismo a la destitución de Vasco López, hubo dos electores que sacaron a relucir las acciones de Vasco López que pudieran ofender al monarca castellano; por lo que conocemos, consistieron éstas en labrar moneda falsa y en haber pretendido tomar por asalto la villa realenga de Almoguera, cargos por los que en Capítulo se le acusó abiertamente de traidor a la Corona. Y no siendo lo anterior suficiente, también le acusaron del mismo cargo por haberse llevado ganados y tesoros de la fortaleza de Montánchez en su reciente huida al reino de Portugal. Ante esta situación, los electores depusieron al maestre Vasco López y acto seguido el rey de Castilla dispuso que "freylasen a Alfonso Mendez de Guzman". De este modo colocó Alfonso XI al frente de la Orden de Santiago a uno de sus oficiales sin ser freire de la misma, al igual que antes había colocado a Gonzalo Martínez de Oviedo al frente de la Orden de Alcántara en idéntica situación.

24. Así en Gran Crónica, p. 251.

25. Rades y Andrada f. 43v, dice que la Orden se reunió en Capítulo General, a pesar de que para la elección no era necesaria una asamblea general de la Orden.

26. Ibidem, f. 43r. Creemos que se refiere a Sancho Sánchez Carrillo, del que dice este autor, folio 45r que antes había sido comendador de Ocaña y luego comendador mayor de Castilla.

27. No podemos asegurarlo, pero los indicios apuntan a que la persona que más influyó en el monarca para que éste nombrara a Alonso Méndez de Guzmán como maestre de Santiago fue su hermana Leonor. Tengamos en cuenta que al morir el maestre en 1342, durante el cerco a Algeciras, los santiaguistas eligieron como maestre de la Orden al infante don Fadrique. Esto último es sobradamente conocido, de lo que no se ha escrito mucho es que doña Leonor estaba por entonces en Tarifa, como se demuestra en la documentación del intercambio de la villa de Lucena con el obispo de Córdoba. Para más datos sobre esta permuta véase García Fernández 1991, pp. 119-128. 
No conocemos fuente alguna que precise la fecha en las que se produjeron estos rápidos y sucesivos cambios en el seno la Orden de Santiago. Contrastando lo narrado por las crónicas con el itinerario real podemos llegar a saber que la muerte del maestre Vasco Rodríguez pudo producirse entre los días 16 de junio y 22 de julio, fechas en las que la cancillería real expide documentación desde Cuenca. Pero dentro de esta horquilla cronológica, y teniendo en cuenta los medios de transporte de la época, así como los estatutos santiaguistas, nos inclinamos a pensar que la fecha de la muerte del maestre Vasco Rodríguez debió estar muy próxima a la primera de ellas; al igual que también creemos que la segunda -22 de julio de 1338- debió ser cercana a la elección de Vasco López en el convento de Uclés. Si atendemos exclusivamente al relato cronístico pudiera parecer que hubo un compás de espera después de la elección de Vasco López, pero no debió ser así cuando la documentación nos permite asegurar que el día 16 de agosto de 1338 ya firmaba Alfonso Méndez de Guzmán como maestre de la Orden de Santiago. El documento en cuestión es la confirmación de la concesión del Fuero de Uclés a Villanueva de Alcardete (Toledo); al ser extendido este documento precisamente en la villa de Ocaña ${ }^{28}$, nos da pie a creer que fuese éste uno de los primeros documentos firmados por el nuevo maestre de la Orden de Santiago.

Pudiera pensarse que la llegada del Alfonso Méndez de Guzmán al maestrazgo santiaguista supusiera la presencia de cambios en la cúspide de la Orden, pero todo apunta a que dichos cambios se produjeron antes. El caso del nuevo comendador mayor del reino de Castilla ${ }^{29}$ nos parece claro, pues entendemos que Sancho Sánchez Carrillo pasó de Ocaña a la encomienda mayor -ubicada en Segura de la Sierra por entonces- para sustituir a Vasco López al frente de la misma. Aunque encontramos más dificultades para explicar lo que ocurrió en la encomienda mayor del reino de León, lo cierto es que poco más tarde de los sucesos de Ocaña encontramos al frente de la misma a Fernán Rodríguez Mexía ${ }^{30}$, quien había sido comendador de Guadalcanal en los últimos tiempos del maestre Vasco Rodríguez.

De Sancho Sánchez Carrillo podemos decir muy poco, aparte de que murió frente a Gibraltar en $1350^{31}$ y que su familia debía ser de la confianza de Alfonso XI, como luego lo fue con su hijo Enrique de Trastámara durante la guerra civil castellana de la década los años sesenta ${ }^{32}$. Por lo que a Fernán Rodríguez Mexía se

28. La fecha la conocemos gracias a una confirmación general de Felipe III a esta villa. En el documento aparece la data de 16 de agosto de "mil y trecientos e sesenta y seis", que corresponde al año 1328. Pero no puede ser 1328 por lo que venimos exponiendo, sino 1338. Para más detalles sobre el documento en cuestión véase Rivera Garretas 1985, documento 244. En esta ocasión Alfonso Méndez de Guzmán confirma, en calidad de maestre, una concesión anterior.

29. No sorprenda que hablemos a lo largo de este trabajo de los comendadores mayores de los reinos de Castilla, León y Aragón. No podemos hacerlo de otra manera cuando en el documento del apéndice, datado en el año 1341, se hace referencia al "comendador mayor del regno de Castilla, ....comendador mayor del regno de León, ... comendador mayor del regno de Aragón”.

30. Concretamente en septiembre de 1339, cuando se produce el choque con los granadinos en Siles. Asunto que veremos más adelante.

31. Así lo podemos leer en AHN, Códice 236-B, f. 122v.

32. Los miembros de la familia Carrillo, como la de los Mexía, fueron hombres de la confianza de Alfonso XI y más tarde de su hijo Enrique de Trastámara. 
refiere podemos decir que conocemos algo más y en ello profundizaremos luego, pues ahora conviene señalar que con la cúspide de la Orden definida el nuevo maestre convocó un Capítulo General a celebrar en la villa de Mérida para el mes de marzo del año siguiente, con la finalidad de tomar contacto con la mayoría de los miembros de la institución y perfilar también la actividad militar de la Orden en un futuro cercano, el cual se presumía complicado a juzgar por los rumores que llegaban de la Frontera.

Y dicho esto, volveremos ahora sobre la persona de Fernán Rodríguez Mexía, apoyándonos en crónicas y genealogistas ${ }^{33}$, tratando de deshacer el error histórico que con este hombre se ha cometido al confundirlo con el ricohombre castellano Fernán Rodríguez de Villalobos. Para ello reiteraremos que Fernán Rodríguez Mexía era comendador de Guadalcanal desde 1332 al menos, y creemos que estaba casado con una mujer del linaje Guzmán ${ }^{34}$, circunstancia esta última que posiblemente jugara en su promoción a comendador mayor del reino de León, al tiempo que explica a la perfección un interesante suceso que ocurrió en septiembre de 1342, al morir el maestre Alonso Méndez de Guzmán en el cerco de Algeciras y ser nombrado como nuevo maestre de la Orden de Santiago al infante don Fadrique. En esta ocasión, en la que el Infante estaba presente en el cerco de Algeciras y su madre en Tarifa, parece razonable que el rey de Castilla designara como tutor de don Fadrique ${ }^{35}$ al comendador mayor de León, casado con una Guzmán como ya hemos dicho, mientras llegaba desde Aviñón la consiguiente confirmación papal al nombramiento hecho en Algeciras. Como anticipamos en su momento, otros autores han dicho ${ }^{36}$ que este tutor del infante don Fadrique era Fernán Rodríguez de Villalobos, pero si leemos atentamente la crónica de Alfonso XI podemos darnos cuenta que cuando llega el señor de Villalobos al frente de su mesnada al cerco de

33. Fundamentalmente seguimos a Sánchez Saus, Rafael, 1991 p. 198, aunque no por ello nos hemos desentendido de Gonzalo Argote de Molina y de Gonzalo Fernández de Oviedo, como veremos luego. No obstante, hemos de precisar que en la documentación santiaguista consultada en el $\mathrm{AHN}=$ (Archivo Histórico Nacional) y RAH = (Real Academia de la Historia), no aparece por estos tiempos ningún comendador mayor que se llamara Ruy González Mexía, como apuntan los genealogistas antes citados. El entonces comendador mayor del reino de León se llamaba Fernán Rodríguez, del linaje de los Mexía, como demostraremos más tarde.

34. Fernández de Oviedo, f. 50r.

35. En el hecho de que el monarca eligiera al comendador mayor de León y no al de Castilla, pudo influir el hecho de que el primero de ellos estaba casado con una Guzmán. Esta circunstancia la encontramos relacionada directamente con la estancia de doña Leonor de Guzmán en Tarifa; en este sentido precisaremos que fue a ella a quien su hermano mandó que se entregara el sello del Capítulo General de la Orden de Santiago, viéndose en peligro de muerte. Este es un asunto que no podemos tratar aquí por su extensión, pero tengamos en cuenta que el maestre guardaba personalmente el citado sello en contra de las disposiciones internas de la Orden; esta distorsión no se solucionó hasta julio de 1350, después de la muerte de Alfonso XI, cuando finalmente el infante don Fadrique devolvió el sello del Capítulo General a tres comendadores de la Orden.

36. La nómina de autores que hablan del señor de Villalobos como comendador mayor del reino de León creemos que comienza con Rades y Andrada, al citarlo así en su crónica sobre las órdenes ya mencionada. 
Algeciras $^{37}$-esto ocurre en el mes de marzo de 1343-, el comendador mayor del reino de León, Fernán Rodríguez, hacía más de un mes que había participado en un acto de carácter político representando al maestre don Fadrique en una visita que al rey de Castilla le hizo una delegación del rey granadino, la cual venía a parlamentar con don Alfonso el levantamiento del asedio sobre Algeciras a cambio de hacer las paces con Granada ${ }^{38}$.

Por el conjunto de circunstancias que se dieron sobre Algeciras, consideramos que Fernán Rodríguez Mexía, comendador mayor del reino de León, nada tiene que ver con su homónimo señor de Villalobos, ni tampoco con el entonces prior de Uclés, también llamado Fernán Rodríguez, personajes ambos a quienes otros autores han elevado a la categoría de tutores del infante don Fadrique.

\section{EL NUEVO MAESTRE Y LA CAMPAÑA DE 1339}

Dejando para más tarde otros aspectos relacionados con el comendador mayor del reino de León, digamos ahora con respecto al nuevo maestre santiaguista que después de su nombramiento a mediados del mes de agosto de 1338 posiblemente continuara unos días en Ocaña. Desconocemos cuánto tiempo permaneció aquí, pero sabemos que a primeros de septiembre, concretamente el día 3, estaba ya en Uclés concediendo al concejo de esta villa los 1.200 maravedíes que al maestre correspondían en concepto de la martiniega ${ }^{39}$, aunque en el documento no se precise si tal cesión era la correspondiente al año en curso o afectaba a la martiniega de años sucesivos.

Mientras tanto el rey se marchó de Ocaña a Madrid y de aquí la Corte pasó a Alcalá de Henares, donde extendió el documento de la permuta de Arcos por Huelva, según vimos más arriba. Por su parte, el maestre siguió visitando las posesiones de la Orden en el reino de Castilla mostrándose generoso con concejos y vecinos; muestra de ello es la exención de ciertas cargas económicas al concejo de Campo de Criptana, declarando que sólo quedaban libres de pecho los hidalgos que mantuvieran caballo y armas ${ }^{40}$. En esta línea, el día primero de diciembre de 1338 confirma en Villamayor la carta-puebla de Villanueva de Alcardete y otras

37. Crónica, p. 356. Por si lo anterior fuese insuficiente, el cronista se recrea hablando de que el rey ordenó al señor de Villalobos que acampara junto a su cuñado Juan de la Cerda, en las proximidades del río de la Miel. Los santiaguistas, por otra parte, acampaban entonces cerca del fonsario musulmán, junto a los vasallos del infante don Fadrique y a los de don Juan Núñez de Lara.

38. Ibidem, p. 353. Para atender esta visita, que se efectuó a primeros de febrero, el rey convocó a los ricoshombres que ya estaban en el cerco y a los maestres de las órdenes militares. Según la Crónica, la de Santiago estuvo representada por don Fernán Rodríguez, "Teniente-logar del Maestre de la orden de Sanctiago".

39. El documento está datado el 3 de septiembre de 1338, en Uclés. Véase así en Rivera Garreta 1985 , p. 467.

40. AHN. Archivo de Uclés $81 / 14$ = (carpeta 81, documento 14). El documento está fechado el día 27 de noviembre de 1338, en Campo de Criptana. Así en Porras Arboledas 1997, p. 455. 
mercedes que beneficiarán a este concejo ${ }^{41}$. Posteriormente el maestre pasó de nuevo por Uclés, villa donde confirma a Villamayor la carta por la que el maestre Vasco Rodríguez elevó a la categoría de villa al lugar de Chozas y le concedió una dehesa ${ }^{42}$. Más tarde el nuevo maestre llegó a Dos Barrios y aquí confirma al concejo la concesión de la heredad de la Serna Nueva que en su día le hiciera el maestre Pelay Pérez Correa ${ }^{43}$.

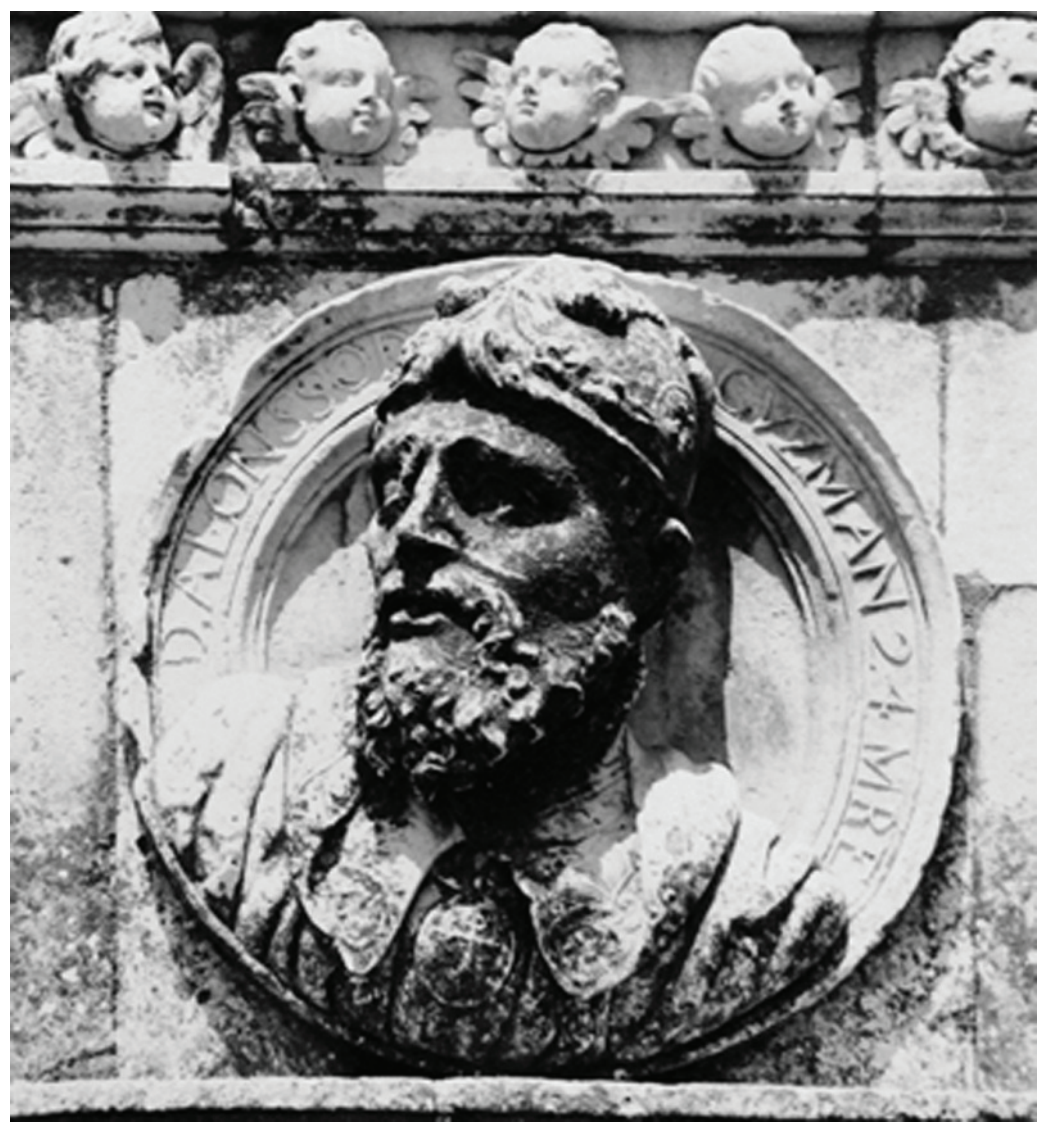

Medallón correspondiente al maestre Alonso Méndez de Guzmán en la fachada principal del convento de san Marcos, en León, En la inscripción figura como vigésimo cuarto maestre de la Orden de Santiago.

41. AHN. Archivo de Uclés 93/33. El documento se extiende en Villamayor de Santiago (Cuenca), el día 1 de diciembre de 1338. El documento está publicado en la misma referencia de la nota anterior.

42. AHN. Archivo de Uclés, 363/1. Está fechado este documento el día 3 de diciembre de 1338, en Uclés. Publicado por Sáez 1953, p. 259.

43. La confirmación del maestre en Dos Barrios (Toledo) se hace el día 10 de diciembre de 1338. Así en RAH. Colección Salazar y Castro, manuscrito M-128, folios 273r-277v. 
No tenemos más información del maestre en tierras de Castilla, pero observamos que a medida que avanza el año 1338 se encuentra más al Sur, por lo que entendemos que su intención era acercarse a las posesiones de la Orden en el reino de León, como luego veremos. En este itinerario, es muy posible que el maestre llegara hasta Villa Real -la actual Ciudad Real-y entrara en las tierras de la Orden por Azuaga (Badajoz), siguiendo un camino que de Villa Real pasaba por Abenójar, Chillón, Fuenteovejuna y Azuaga ${ }^{44}$. Desde esta última el maestre llegaría a Llerena, encomienda perteneciente a la Mesa Maestral, y luego se presentó en Montemolín -entonces sede de la Encomienda Mayor del reino de León- el día 3 de enero de $1339^{45}$. Su paso por esta villa está documentado, como también lo está su presencia en Monesterio unos días más tarde ${ }^{46}$, para llegar a Mérida a primeros de marzo con el fin de celebrar el Capítulo General que se había convocado, situación ésta que queda reflejada en la documentación de la época.

La celebración del Capítulo General de la Orden, a primeros de marzo de 1339 en la villa de Mérida, la conocemos por un documento donde el nuevo maestre confirma su Fuero a la villa de Llerena, momento en el que le concede otras ligeras concesiones al concejo ${ }^{47}$. Todo apunta a que el maestre Méndez de Guzmán trataba de atraerse a los concejos atendiendo a las quejas presentadas por sus vecinos y el caso de Mérida y sus aldeas no fue una excepción; no lo fue porque en aquel Capítulo General, que debió comenzar el día primero de marzo de 1339, se quejaron los emeritenses de los muchos perjuicios que los pastores y ganados del maestre, así como el de los comendadores y freires de la Orden, causaban en las dehesas del concejo hasta el punto de tener que comprar dehesas para sus ganados fuera de los términos de Mérida. Como estos abusos iban en contra de lo que disponía el Fuero de Mérida, el maestre se opuso abiertamente a tales abusos y exigió a los miembros de la Orden que a partir de entonces se ciñeran a cuanto disponía el fuero emeritense $\mathrm{e}^{48}$.

Puede que Alfonso Méndez de Guzmán permaneciera en Mérida durante una larga temporada, aunque lo más probable es que aprovechara entonces para visitar por las villas y lugares más cercanos volviendo de nuevo a la villa del Guadiana; desde luego aquí estaba a mediados del mes de abril cuando extendió otro documento que también afectaba al concejo emeritense. En dicho documento el maestre dispone que el alcalde de la Orden no juzgara los pleitos relativos a los vecinos del concejo, que el yantar correspondiente al maestre fuese pagado debidamente cuando éste viniera a Mérida, que se abonasen debidamente los portazgos y montazgos, y que todos los vecinos pagaran su pecho, exceptos los paniaguados ${ }^{49}$.

44. Crónica, p. 246. Este camino ya fue utilizado por Alfonso XI para llegar de Toledo a Sevilla camino de Gibraltar. Véanse más detalles en López Fernández 2005b, pp. 185-207.

45. Así podemos verlo en López Fernández 2015, pp. 13-58.

46. Concretamente el día 9 de enero. Véase el trabajo de la nota anterior.

47. La confirmación del Fuero a Llerena la hizo el maestre en Mérida el día 6 de marzo de 1339. Así en López Fernández 2005a, pp. 243-257.

48. Sobre el citado Fuero véase Porras Arboledas 2012, pp. 27-48.

49. Archivo Municipal de Mérida. Privilegios Reales. Carta de privilegio del maestre Alfonso Méndez, extendida el día 13 de abril de 1339. 
Dada la fecha de la extensión del documento que acabamos de citar, es posible que el maestre de Santiago esperara en tierras de la Orden -ya en Mérida o en otro lugar situado más al Sur- el paso del rey hacia Sevilla; lo creemos así porque el día 24 de mayo el monarca pasaba por Trujillo (Cáceres) y el 4 de junio queda localizado su paso por Fuente del Maestre (Badajoz). Con lo anterior pretendemos decir que no andamos muy descaminados al pensar que el maestre de Santiago acompañara al rey de Castilla a su paso por tierras de la Orden y que llegara a Sevilla a mediados del mes de junio con la comitiva real ${ }^{50}$.

Lo que resulta seguro es que un mes más tarde, formado ya parte de las fuerzas castellanas que se encaminaba hacia la frontera de Granada, el maestre de Santiago al frente de las huestes de la Orden pasaba por Alcalá de Guadaira camino de Antequera, villa sobre la que estuvieron varios días; mientras el rey estragaba las tierras de Antequera, mandó al maestre de Santiago y a otros nobles castellanos que talaran las tierra de Archidona, para llegar a Ronda poco después ${ }^{51}$. Sobre esta villa estuvieron también unos días causando destrozos en las cosechas y antes de que faltaran las viandas en la hueste castellana emprendieron el camino de vuelta, por Ortejícar y $\mathrm{Teba}^{52}$, formando las fuerzas de la Orden de Santiago en la retaguardia de aquella marcha.

Don Alfonso había decidido regresar a Sevilla a primeros del mes de agosto ${ }^{53}$, porque tenía que irse a Madrid, donde pensaba reunir Cortes. Pero llegado septiembre, temiendo que el rey de Granada o el infante Abu Malik desde Algeciras pudieran realizar una incursión armada sobre algún lugar del reino castellano, se acordó en Sevilla que los efectivos reunidos para la campaña de aquel año se distribuyeran a lo largo de la frontera granadina para atender cualquier contingencia. Siguiendo este plan, una parte de aquellas fuerzas se desplazaron a Jerez y Arcos, otras a Córdoba ${ }^{54}$, mientras al maestre de Santiago se le encargó que se situara con sus fuerzas en Úbeda ${ }^{55}$. Al poco tiempo de llegar aquí se enteró el maestre de que tropas granadinas bajo el mando de arráez de Guadix ${ }^{56}$ tenían cercada la villa santiaguista de Siles, por lo que pidió ayuda a la gente de las villas del obispado de Jaén, consiguiendo reunir de esta manera un contingente de mil hombres de a caballo y dos mil hombres de a pie, fuerzas con las que acudió a socorrer a los cercados.

50. Estas circunstancias podemos verlas en Cañas Gálvez 2014, p. 341.

51. Gran Crónica, p. 260 y 261.

52. Crónica, p. 297.

53. Así podemos verlo por Cañas Gálvez 2014, p. 343. También en Crónica, p. 297. Igualmente en Gran Crónica, p. 261.

54. La gente de Jerez quedó bajo el mando del obispo de Mondoñedo, las de Arcos bajo el de Fernando Pérez Ponce y las de Córdoba a las órdenes del maestre de Alcántara, quien ejercía entonces como adelantado mayor de La Frontera.

55. Crónica, p. 298. También en Gran Crónica, p. 362.

56. En Gran Crónica, p. 268 se dice que el arráez granadino se llamaba Yahya Aboamar. 
Según las crónicas, los granadinos, que en caballería duplicaban a los castellanos y le triplicaban en el número de peones ${ }^{57}$, al enterarse de la proximidad de las tropas castellanas abandonaron el cerco y se dispusieron a hacerles frente. El maestre, al percatarse de la situación, hizo ver a sus tropas el peligro que corría la villa de Siles arengándoles al enfrentamiento con los de Granada a pesar de la desventaja numérica existente, razón por la que algunos llegaron a aconsejarle que no comenzara la pelea; pero el maestre rechazó tal proposición alegando que no podían ayudar a los de Siles sin enfrentarse a las fuerzas del rey de Granada, para lo que apeló al prestigio del linaje de los Guzmán diciendo que éste no era menor que el de otros maestres que le habían precedido al frente de la Orden. Así que, después de pedir a los suyos que cada uno hiciera el mayor esfuerzo posible, ordenó a su alférez que arremetiera contra los granadinos, comenzando entonces una indecisa batalla que se decantó favorable a los cristianos cuando consiguieron derribar al arráez de Baza, pariente del rey de Granada, momento en el que los granadinos emprendieron la retirada dejando en el campo de batalla un abundante botín para los del maestre.

La Crónica no da los nombres de aquellos que acompañaban al maestre en tan decisiva ocasión, pero la Gran Crónica, más generosa en detalles, nos habla de la intervención del comendador mayor de León, Fernán González (sic) Mexía, y de la de Sancho Sánchez Carrillo, comendador mayor de Castilla ${ }^{58}$. De estos dos personajes, el que nos interesa aquí, con el fin de determinar el linaje al que pertenecía, es el del entonces comendador mayor del reino de León, cuyo apellido no coincide con el que nos proporciona la documentación santiaguista de la época ${ }^{59}$, circunstancia nada extraña si tenemos en cuenta que la Gran Crónica fue escrita en el reinado de Enrique II, más de treinta años después de que ocurrieran los hechos que ahora relatamos ${ }^{60}$. No obstante, en otra fuente castellana más cercana a los acontecimientos, pues se escribió en 1348, también se recogieron los hechos que venimos narrando; en este caso nos referimos al Poema de Alfonso el Once$n o^{61}$, obra escrita cuando posiblemente viviera el comendador mayor del que ahora hablamos ${ }^{62}$.

En una de las coplas donde se relata el enfrentamiento de Siles nos dice el poeta $^{63}$ :

57. Por lo que señalan las fuentes cristianas que seguimos, en el caso de los de a caballo le doblaban los granadinos y, respecto a los de a pie, llegaban a triplicarle. Ponemos en reserva la veracidad de estas fuentes.

58. Gran Crónica, p. 267.

59. Como hemos dicho, en la documentación santiaguista el comendador mayor del reino de León por aquellos años se llama Fernán Rodríguez sin precisar a qué familia pertenecía.

60. Gómez Redondo 1999, pp. 1.816-1.817.

61. Yáñez 1966, p. 499.

62. Desde luego, el autor de un códice santiaguista lo considera vivo en 1348 siendo comendador mayor de León y de Montemolín; era así porque aquí estaba la sede de la Encomienda Mayor de León. Véase AHN. Códice 314-B, folio 97v.

63. Conviene precisar que estos versos los reproduce también Argote de Molina 1957, p. 402. 


\author{
"A los Moros bien feria \\ el Maestre Real Varon \\ e don Ferrando Mexia \\ Comendador de Leon. \\ El Arraz torno omeziello \\ con sus Moros fiz manziella \\ con Sancho Sanchez Carriello \\ Comendador de Castiella".
}

Por lo que vemos, el autor del citado poema deja suficientemente claro que el comendador mayor del reino de León que intervino en la batalla de Siles en 1339 pertenecía al linaje Mexía, y no al de Villalobos. Visto lo cual, terminaremos este apartado diciendo que después de la batalla el maestre Méndez de Guzmán, por demostrar en la Corte la dimensión de su victoria, envió a Madrid varios sacos llenos con las orejas de los granadinos que habían caído en el combate, gesto que hoy nos puede resultar chocante, pero que fue agradecido por el rey de Castilla ${ }^{64}$.

\title{
4. La Orden de Santiago en la batalla del Salado
}

Después de mandar que se repararan los muros de la villa de Siles, el maestre debió finalizar el año en tierras de la Orden, pero lamentablemente carecemos de información documental precisa para fijar su itinerario durante los meses finales del año 1339 y buena parte de 1340. Aunque las crónicas reales no lo mencionan hasta el mes de septiembre de este último año, estando ya en Sevilla, existen motivos fundados para creer en la posibilidad de que estuviese en la capital del Guadalquivir desde finales del mes de febrero, si nos apoyamos una vez más en el itinerario del rey de Castilla y a su paso por tierras de la Orden de Santiago en su camino desde el alfoz de Trujillo a Sevilla.

Alfonso XI comenzó el año 1340 en Madrid y luego se fue a cazar a tierras de Trujillo, pasando antes por Talavera. Para entonces ya eran manifiestas las desavenencias del rey de Castilla con Gonzalo Martínez de Oviedo, surgidas a raíz de la postura de éste ante el nombramiento de Alfonso Méndez de Guzmán como maestre de Santiago, situación que desagradó a Leonor de Guzmán ${ }^{65}$. Las cosas habían llegado a un punto de difícil retorno entre el monarca y el maestre alcantarino, por lo que éste abandonó la Frontera y se encastilló en la fortaleza de Valencia de Alcántara. Aquí vino Alfonso XI a pedirle cuentas y se encontró con la franca rebeldía de Martínez de Oviedo, por lo que el acabó declarándole traidor y decretando su muerte ${ }^{66}$.

64. Gran Crónica, p. 268.

65. Ibidem, p. 291, aquí se dice literalmente que la inquina de doña Leonor hacia Martínez de Oviedo fue: “...por querer estovar a su hermano, don Alonso Mendez, que no fuese maestro de Santiago".

66. Ibidem, p. 300. 
Después de superado este asunto, el rey se fue a cazar a Robledillo ${ }^{67}$, en las cercanías de Montánchez, lugar donde lo encontró el alcalde de las atarazanas de Sevilla, Alonso González ${ }^{68}$, quien le buscaba para explicarle la apremiante situación en la que se encontraba la flota castellana en aquellos cruciales momentos $^{69}$, motivo por el cual el monarca se dirigió a Sevilla a toda prisa. En este desplazamiento, forzosamente hubo de pasar el monarca por tierras de la Orden de Santiago -tal vez por Montánchez, Mérida, Llerena ${ }^{70}$ y Guadalcanal- antes de llegar a Sevilla a finales del mes de febrero ${ }^{71}$. No podemos asegurar que en una de estas plazas estuviese el maestre de la Orden, pero en alguna de ellas debía estar el comendador mayor del reino de León, Fernán Rodríguez ${ }^{72}$, quien procedería a informar a su maestre de aquel cambio de planes que había provocado la rápida llegada del monarca a Sevilla.

Como la situación en el Estrecho no hizo más que agravarse para Castilla a partir de la derrota naval de Getares ${ }^{73}$-el 8 de abril de 1340-, y el rey estuvo toda la primavera y el verano entre Jerez y Sevilla, no creemos que el maestre de la Orden de Santiago estuviese muy alejado de Alfonso XI. De todas maneras, ya a finales del mes septiembre, la Crónica nos habla de una reunión en Sevilla en la que se menciona concretamente la presencia de Alfonso Méndez de Guzmán entre los principales personajes de la Corte ${ }^{74}$. Unos días después, ya a primeros de octubre, cuando se había producido un nuevo desastre que afectó a la flota que operaba en Tarifa, la Crónica vuelve a situar al maestre junto al monarca ${ }^{75}$ cuando éste informa a los nobles castellanos de su clara intención de ir a descercar la villa del Estrecho con la ayuda del rey de Portugal, todo ello después de la entrevista que había tenido con Alfonso IV en Jurumena y Badajoz.

Unos días después llegaba el rey portugués a Sevilla y, sin demora alguna, el ejército castellano-portugués se puso en camino hacia Tarifa para llegar a la Peña del Ciervo en la mañana del día 29 de octubre. Aquella misma tarde, una vez que visualizaron la disposición de los efectivos musulmanes que le cortaban el paso, Alfonso XI reunió su consejo para disponer el orden de batalla que habían de

67. Actual Robledo de Trujillo, en la provincia de Cáceres.

68. Así en Ortiz de Zúñiga 1795, libro V, p. 99.

69. Gran Crónica, p. 308. Por lo que aquí leemos, al almirante Jofre Tenorio se había quejado de que le faltaban medios navales y humanos para combatir con eficacia cualquier agresión proveniente de los musulmanes.

70. En esta ocasión nos inclinamos por el paso del rey por Llerena a tenor de que en 1340 se celebraron aquí Cortes, según veremos en el apartado final de este trabajo. Suponemos que el rey de Castilla debía conocer esta población con antelación a aceptarla como lugar idóneo para una reunión de Cortes, con lo que ello suponía en el aspecto logístico.

71. Cañas Gálvez 2014, p. 353.

72. No olvidemos que la Encomienda Mayor del reino de León estaba entonces en Montemolín (Badajoz).

73. López Fernández 2007, pp.135-162.

74. Para el desarrollo de los acontecimientos del año 1340, al aportar más detalles, seguiremos a la Gran Crónica. En la misma se dice, pp., 349-350, que fue en esta asamblea donde el rey de Castilla explicó a los señores del reino que Tarifa había sido cercada.

75. Ibidem, p 379. El desastre naval ocurrió en la noche del 5 al 6 de octubre. Los detalles que precisan esto último lo podemos encontrar en un trabajo de López Fernández 2017, en prensa. 
adoptar el día siguiente. Según indica la Gran Crónica $^{76}$, a esta asamblea asistió el maestre de la Orden de Santiago y en ella se acordó que las huestes santiaguistas formaran en la vanguardia, al mando de don Juan Manuel; una vez constituida esta vanguardia a la gente de la Orden de Santiago le correspondió luchar al lado de las huestes de don Juan Núñez de Lara, señor de Vizcaya.

En la mañana del día 30 de octubre de 1340, la Orden desplegó sus efectivos en los tropeles del ala izquierda de aquella vanguardia; cuando ésta llegó al curso del Salado detuvo el avance por decisión de don Juan Manuel y allí estuvieron esperando a lo largo del tiempo suficiente como para que las fuerzas del rey de Castilla -que componían el ala derecha del despliegue cristiano- llegaran al Salado. El monarca mandó aviso a don Juan Manuel para que avanzara, pero éste se mantuvo a la espera mientras que las fuerzas que estaban bajo el mando del rey de Portugal -ala izquierda del ataque cristianoretrocedían ante el empuje de los musulmanes de Granada, momento en el que intervino la reserva bajo el mando de Pero Núñez de Guzmán. Esta situación obligó a desplazar efectivos benimerines para ayudar a los granadinos y, como consecuencia de ello, se produjo una debilidad en las líneas norteafricanas por las que penetraron las huestes de don Juan Núñez de Lara y del maestre de la Orden de Santiago después de cruzar el Salado. ${ }^{77}$ El combate se hizo aquí muy duro, pero los santiaguistas y vizcaínos consiguieron avanzar hasta conseguir enlazar con otro tropel de la vanguardia que trataba de afianzar su posición en una pasada situada más abajo.

La lucha allí se decantó finalmente del lado cristiano y en su retirada los benimerines comenzaron a huir hacia cotas más altas, de manera que los de don Juan Núñez y los del maestre de Santiago le siguieron hasta llegar al mismo campamento del sultán, donde se encontraron con la disminuida guarnición del mismo ya que, parte de la misma, había bajado por una vaguada con la intención de detener el ataque de los defensores de Tarifa, quienes a su vez habían llegado desde la villa en una sorprendente salida realizada a espaldas del despliegue musulmán $^{78}$. A causa de estas coincidentes maniobras, en la zona del campamento benimerí se encontraron los efectivos de la Orden de Santiago, los de don Juan Núñez y los que habían salido de Tarifa; todos juntos, no tardaron en hacerse con el control del campamento tras poner en franca retirada a todos los efectivos que lo guardaban. Después de adueñarse de aquellas lomas y saquear el campamento, este grupo de hombres descendió atacando de flanco a las fuerzas

76. Ibidem, p. 412.

77. Ibídem. Los pasos que vamos describiendo se relatan entre las pp. 426 y 430 . El cruce del Salado se relata en la p. 428, respecto al mismo precisaremos que este movimiento debió producirse con posterioridad a la entrada en acción de la reserva cristiana, la fuente que seguimos la cuenta antes porque no sigue un proceso sincrónico de la batalla en su conjunto, sino que va describiendo lo que ocurre en los diferentes sectores del terreno.

78. La noche antes de la batalla, un potente contingente cristiano había reforzado la guarnición de Tarifa después de un peligroso desplazamiento a lo largo de la costa, entre el campamento cristiano y la cercada villa de Tarifa. 
marroquíes ${ }^{79}$ y provocando un descalabro total en el ejército norteafricano, que terminó con la huida de sus componentes hacia Algeciras, siendo perseguidos por los cristianos hasta el río Guadalmesí.

No vamos a entrar en detalles sobre los asuntos relacionados con los actos que se celebraron después de aquella victoria ni del rápido regreso de los componentes del ejército castellano portugués a Sevilla, debido a la escasez de provisiones que padecían. Y aunque en la Gran Crónica se termine con las referencias al maestre de la Orden de Santiago en el ataque al campamento de los benimerines, no hay dudas respecto a la proximidad de Alonso Méndez de Guzmán al monarca castellano; no las hay porque en unas fechas próximas a la batalla, tal vez al tiempo que se transmitía por su reino el brillante triunfo conseguido, pensó el monarca en convocar Cortes y el lugar elegido para esta reunión fue Llerena, villa de la Orden de Santiago como ya sabemos, por lo que hubo de contar con la voluntad del maestre. No existen cuadernos de estas Cortes, pero conocemos los suficientes datos para decir que fueron citados a las mismas dos representantes de las ciudades y villa de los reinos de Castilla y de León, como luego veremos, por lo que hubo de enviarse notificación a los concejos del reino con antelación suficiente.

Después de la brillante victoria conseguida en los campos de Tarifa, los reyes emprendieron el camino de vuelta a Sevilla sin dejar de pasar por el santuario mariano que existía en el actual Puerto de Santa María ${ }^{80}$. La fecha exacta de la entrada en Sevilla la desconocemos, pero debió ser antes del día 12 de noviembre porque en ese día ya despachaba la cancillería del rey de Castilla en la capital del Guadalquivir; ambos monarcas continuaron juntos unos días más antes de que el rey de Portugal emprendiera el camino hacia su reino y, aunque Alfonso XI le acompañó hasta la actual Cazalla de la Sierra ${ }^{81}$, es de suponer que el maestre de Santiago le siguiera hasta Llerena. Lo creemos así porque desde Cazalla el camino hacia Portugal pasaba forzosamente por Guadalcanal y Llerena, villa ésta donde se reunieron las Cortes poco después.

El rey de Castilla, por otra parte, se desplazó de Cazalla a Carmona ${ }^{82}$ y luego tomó el camino de Llerena, donde debió llegar antes del día 30 de noviembre a tenor de la documentación citada por Francisco de Paula Cañas Gálvez ${ }^{83}$. A juzgar por la misma, parece que las Cortes de Llerena se prolongaron durante varios días $\mathrm{y}$, entre tales documentos, cabe destacar la carta dirigida al concejo de Miranda de Ebro sobre la judería - extendido el día 8 de diciembre-, en la que se habla de dicha reunión como cosa ya celebrada, al tiempo que se menciona la participación en ella de dos representantes de las ciudades y villas del reino. Esta última circuns-

79. Gran Crónica, p. 431. Aquí se relata sobre los que habían atacado el campamento benimerí: "que auian ydo a do estaua el alfaneque auien uençido los moros que guardavan los rreales e deçian el rrecuesto ayuso matando e feriendo en los moros...".

80. Ibídem, p. 438. Estos actos de carácter religioso continuaron luego en Sevilla.

81. Ibidem, p. 443. En los montes de esta población estuvieron cazando ambos reyes unos días.

82. Ibídem, p. 443. Aunque este desplazamiento resulta extraño, así lo indica la fuente que seguimos.

83. Cañas Gálvez 2014, p. 362. Aquí se cita una serie de documentos extendidos en los días que se celebraron Cortes en Llerena. 
tancia nos lleva a reiterarnos en que la convocatoria de Cortes hubo de hacerse en Tarifa, antes de la dispersión del ejército, y también queremos pensar que Llerena fue elegido como lugar de reunión por sugerencia del maestre santiaguista.

A tenor de lo que venimos exponiendo, no hay dudas por nuestra parte de que el maestre Alonso Méndez de Guzmán, y también el comendador mayor del reino de León, estuvieron en Llerena por aquellas fechas acompañando al monarca en sus quehaceres de gobierno, antes de que éste emprendiera el camino de Guadalupe para dar gracias a la Virgen por la victoria conseguida en tierra próximas al Estrecho.

\section{5.-Las campañas sobre Alcalá de Benzaide, Benamejí y Algeciras}

Por aquellos años la actividad guerrera del rey de Castilla parecía no tener fin y en ella involucró a la Orden de Santiago, como venimos viendo. Por lo que al maestre Méndez de Guzmán se refiere, no sabemos dónde pudo estar durante los primeros meses del año 1341; nos resulta imposible precisar si desde Llerena acompañó al monarca a Guadalupe y a Madrid, o por el contrario estuvo visitando tierras bajo su jurisdicción. De una manera u otra, a principios de abril de 1341 lo suponemos ya en Córdoba ${ }^{84}$ como respuesta a la convocatoria de Alfonso XI para operar en la frontera de Granada. Sin que podamos asegurarlo, puede que ya participara en la primera incursión que el monarca hizo sobre Alcalá de Benzaide -hoy Alcalá la Real-, acompañado de los concejos de Sevilla, Córdoba, Écija y Carmona, mientras llegaban los ricoshombres que habían de venir de los reinos de Castilla y de León ${ }^{85}$.

Llegado el grueso de estas fuerzas, el rey pregonó a los cuatro vientos que quería atacar la ciudad de Málaga y, para demostrar su intención, salió de Córdoba con su hueste camino de Écija. Pero siendo el verdadero objetivo de aquella incursión la villa de Alcalá de Benzaide, Alfonso XI se desvió hacia Baena y por aquí se presentó de nuevo, e insospechadamente para los granadinos, ante la villa de Alcalá, a la que puso cerco a finales del mes de mayo ${ }^{86}$. Formando parte de las huestes castellanas participaba en este cerco la Orden de Santiago, encabezadas por su maestre; tanto era así que en Alcalá, el día 14 de julio, el maestre llegó a un acuerdo con Pedro de Villanueva, hijo de Vidal de Villanueva -comendador mayor de los santiaguistas en reino de Aragón-, por el cual la Orden de Santiago intercambiaba con el primero de ellos ciertas posesiones situadas en el reino de Valencia ${ }^{87}$.

84. Ibidem, pp. 367.

85. Volvemos a citar por Crónica, p. 331.

86. Cañas Gálvez, 2014, p. 368.

87. AHN. Uclés, 307/5. Actualmente, Sellos 101/2. El contenido de este documento figura en el apéndice documental de este trabajo. 


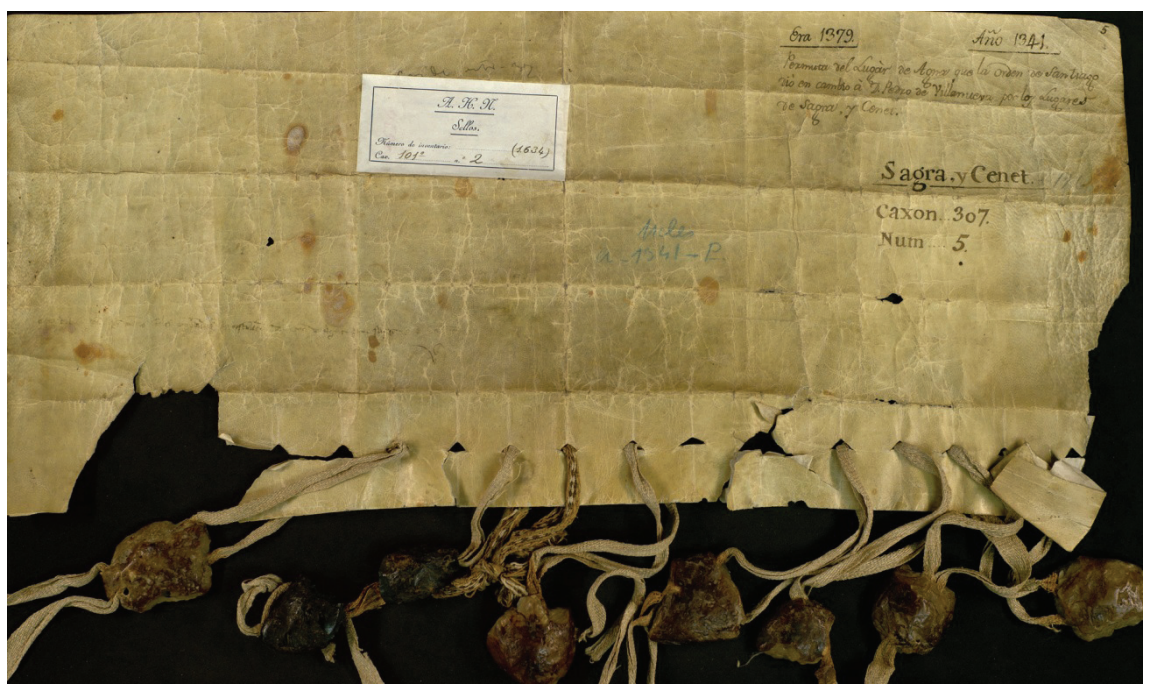

Este es el documento del acuerdo entre la Orden de Santiago y don Pedro de Villanueva, extendido en julio de 1341, durante el cerco a Alcalá de Benzaide. Un simple vistazo a los sellos que cuelgan del mismo justifica que hoy se guarde en la seción de Sellos del Archivo Histórico Nacional.

El documento del intercambio resulta interesante desde el punto de vista sigilográfíco ${ }^{88}$, por los datos que aporta relativos al intercambio $\mathrm{y}$, especialmente, porque en el mismo figura el nombre de los miembros de la cúpula de la Orden en 1341, al realizarse el intercambio de propiedades con el consentimiento de los mismos. Así vemos que en el acto están presentes, además del maestre, los priores de los conventos de San Marcos y Uclés -Gonzalo Yáñez y Fernán Rodríguez respectivamente- y los comendadores santiaguistas más importantes del momento, entre los cuales encontramos a Sancho Sánchez como comendador mayor de Segura y del reino de Castilla, mientras que Fernán Rodríguez lo era a su vez de Montemolín y del reino de León; por lo que se dice aquí, Vidal de Villanueva era el comendador de Montalbán y del reino de Aragón, y al estar ausente le sustituye ${ }^{89}$ Gonzalo Gómez, comendador del Corral de Almaguer. A continuación de los comendadores mayores encontramos a Ruy Gómez de Manzanedo, como comendador de Montemolín, y a Álvar Núñez de Guzmánº, del que no se dice la encomienda que entonces gobernaba, aunque debía ser una del reino de León. Le siguen luego otros comendadores del reino de Castilla, como Men Vázquez,

88. Por el gran número de sellos que colgaban del mismo, según se puede apreciar en la fotografía que adjuntamos. En su día debieron colgar 16, pero hoy sólo le quedan 7 muy deteriorados la mayoría de ellos.

89. Lo cierto es que en el documento que ahora seguimos se dice: .... "enmienda por él".

90. Álvar Núñez de Guzmán ya era comendador mayor del reino de León en 1350. Este hombre fue hijo de otro Alvar Núñez, hijo a su vez de Pero Núñez de Guzmán y de Urraca Alfonso (hija ilegítima de Alfonso IX de León y Teresa Gil). Así en Sánchez Saus 1991, p. 109. 
comendador de Uclés, Martín Hurtado, comendador de Ricote, Fernán Rodríguez, comendador de Oreja, Fernán Ruiz de Tauste, comendador de Segura, y Diego López de Caparroso, comendador de Montiel. A continuación figura Juan López (de Baeza), comendador de Destriana, pero como está ausente "enmienda" por él su hermano, Pero López (de Baeza), comendador de Mérida e de Canena, finalizando la relación de comendadores con Diego Arias, comendador de Socovos, y Alfonso Gómez, comendador de Hornachos.

Después de la fecha de extensión de este documento, el cerco sobre Alcalá se prolongó todavía algún tiempo antes de que los defensores entregaran la villa y su fortaleza al rey de Castilla. Por estas fechas, el rey de Granada pidió ayuda militar a Algeciras e intentó romper el cerco cristiano sin conseguirlo por la rápida reacción de Alfonso XI, quien se plantó con parte de su hueste en las proximidades del campamento de los granadinos con la intención de tenderle un celada, en las que hicieron de cebo las fuerzas de la Orden de Santiago dirigidas por su maestre ${ }^{11}$ en un par de ocasiones. Lo musulmanes granadinos no cayeron en la trampa y poco después los de Alcalá entregaban la villa al monarca castellano en una fecha desconocida para nosotros, pero anterior al día 15 de agosto, pues en esta fecha ya estaba el rey de Castilla cercando Priego ${ }^{92}$ después de reforzar la recién conquistada villa. Priego, por otra parte, no tardó en caer ante las fuerzas castellanas y éstas dirigidas por el rey avanzaron luego sobre Rute al tiempo que las del maestre de la Orden de Santiago lo hicieron sobre Benamejí, antigua encomienda santiaguista que volvió a caer en poder de los granadinos en julio de $1333^{93}$, cuando Alfonso XI sitiaba Gibraltar. Alfonso Méndez de Guzmán cercó el castillo de Benamejí a lo largo de tres días hasta que cayó en sus manos a finales del mes de agosto, por lo que suponemos que a continuación los santiaguistas también participaron en el cerco a Rute, villa que resistió el asedio del monarca castellano unos diez días ${ }^{94}$.

A primeros del mes de septiembre se presentaron las primeras lluvias otoñales, por lo que el rey decidió volver con todas sus fuerzas a Sevilla, desde la que emprendió camino a Madrid con el ánimo de resolver asuntos económicos de cara a la campaña del siguiente año, mientras parece que dejaba al maestre de Santiago como máxima autoridad militar de la Frontera, según leemos en la Crónica ${ }^{95}$. Sin embargo, puede que a finales del otoño la relajada situación de las tierras fronterizas quizás le animara a pedir autorización para alejarse de las mismas en

91. Esto ocurrió después de la entrega de Locubín y de la tala de Pliego. Véase así en Crónica, p 334.

92. De esta fecha es una carta de Alfonso XI a Pedro IV de Aragón pidiéndole que tome medidas sobre aquellos que han huido a este reino con parte del botín obtenido en la batalla del Salado. Véase la misma en López Fernández 2008, pp. 10-16.

93. Este castillo fue tomado por el rey de Granada en una incursión que hizo por tierras fronterizas en 1333, antes de venir en ayuda del infante Abu Malik cuando Alfonso XI sitiaba Gibraltar. Véanse más detalles en Gran Crónica, tomo I, p. 57.

94. Estos detalles se relatan en Crónica, p. 334.

95. Ibidem, p. 335. y 338. En la primera referencia ya se deduce que el maestre quedó al mando de las fuerzas de la Frontera, entre las cuales estaban las otras órdenes militares. En la segunda, cuando el cronista habla del rey de Castilla se dice: "porque ovo nuevas que don Alfonso Mendez maestre de Santiago que él dexara por cabdillo en la frontera, era flaco et llegado a grand enfermedad". 
el invierno y volver a finales de primavera, dejando al frente de las huestes de la Orden a los comendadores mayores de los reinos de Castilla y de León ${ }^{96}$. No podemos asegurar lo anterior, pero la información que nos transmite la documentación santiaguista es que el maestre Alonso Méndez de Guzmán se alejó de Andalucía. El primer documento que así lo demuestra es aquel en el que la Orden concede a Puebla de Almuradiel el Fuero de Uclés y la segrega de Corral de Almaguer. El documento está extendido por el maestre Méndez Guzmán en Ocaña ${ }^{97}$ el día 21 de diciembre de 1341. Casi un mes más tarde, el 24 de enero, la documentación nos muestra que el maestre seguía todavía en Ocaña, cuando la Orden concedió a Pedro Sánchez de Burgos ciertas posesiones en tierras castellanas ${ }^{98}$. Ya en 1342 tenemos localizado al maestre en Utrilla (Teruel), el día 15 de abril, entregando a doña Guiralda de Besora el priorazgo del convento femenino de Santa María de la Junquera con ciertas condiciones ${ }^{99}$. A partir de aquí, el maestre parece encaminarse hacia la frontera granadina y lo encontramos en Montiel el día 4 de mayo, confirmando al concejo de Segura de la Sierra los privilegios concedidos por maestres anteriores ${ }^{100}$. Y todavía unos días más tarde, el día 24 de mayo concretamente, aparece en otro documento extendido en Montiel por el cual el maestre santiaguista confirma lo anterior y otorga nuevos derechos a vecinos de Segura de la Sierra ${ }^{101}$.

Por la forma y contenido de dichos documentos, todos ellos parecen indicar que el maestre Méndez de Guzmán estaba presente en el momento de extender los mismos, pero tal circunstancia entra en clara contradicción con el sentido del relato cronístico, el cual parece transmitirnos que el maestre permaneció en la Andalucía castellana durante la ausencia del rey, aunque no pudo ser así si nos atenemos a la documentación. Fieles a ésta, nos atrevemos a decir que en los días finales del mes de mayo pudo llegar el maestre a Úbeda ${ }^{102}$, cayendo gravemente enfermo al poco tiempo. Tal circunstancia debió llegar a oídos del rey de Castilla ${ }^{103}$, y como

96. Volvemos a hablar de Sancho Sánchez Carrillo y de Fernán Rodríguez Mexía. Es posible que el primero de ellos se hiciera cargo del sector fronterizo de los antiguos reinos de Córdoba y Jaén, mientras el segundo hacía lo mismo en el reino de Sevilla.

97. En el documento se lee: "Sepan cuantos esta carta vieren como Don Alfonso Méndez ..... E desto mandamos dar carta sellada con nuestro sello de cera colgado. Dada en Ocaña, veynte e un días de diciembre era de mil e trecientos setenta e nueve años".

98. AHN. Uclés, 94/61. Todo lo que tenía la Orden en Burgos, Pampliega, Villalquirán, Torre Morante, Iglesias, Bilvestre , Condemuñoz, Palenzuela, Castil de Solana, Lerma y Belorado, exceptuando lo que ya tenían doña Juana, madre de Juan Muñoz, Garci Laso de la Vega, Ramiro Flores de Guzmán y Fernando Sánchez de Valladolid.

99. AHN. Uclés, 262/13. Que mantenga un capellán en su iglesia y que no admita para el hábito a una sobrina de doña Saura de Aguafría, ni mantuviera a costa del convento a Ferrer de Cigar, por razón de las cortas rentas que tenía el monasterio.

100. Porras Arboledas 2014, pp. 14 y 20.

101. El documento está fechado en Montiel el día 24 de marzo de 1342. Véase así en: Documentos de los siglos XIV y XV. Señoríos de la Orden de Santiago. En Colección de Documentos para la Historia del Reino de Murcia, XVII. Edición de Miguel Rodríguez Llopis. Murcia, 1991, documento 7.

102. Dada la posición geográfica de Montiel y Úbeda, suponemos que el maestre pudo hacer su entrada en Andalucía por esta villa.

103. Así se da a entender en Crónica, p. 338. Aquí se dice: “ovo nuevas que Don Alfonso Mendez maestre de Santiago, que el dexara por cabdiello en la frontera, era flaco et llegado a grand enfermedad". 
aquel año el monarca había dispensado a los ricoshombres su presencia en Andalucía ${ }^{104}$, don Alfonso, que estaba entonces en Madrid $^{105}$, decidió tomar el camino de Sevilla por entender que ${ }^{106}$

"si acaesciese muerte del Maestre don Alfonso Mendez, que las gentes que estaban
en la guerra se acabdillarian mejor por su mandado [por el del rey] que non de
otro nenguno que el enviase para esto".

Así las cosas, el rey dejó Madrid en la primera decena de junio ${ }^{107}$ y emprendió un rápido desplazamiento - sin su Cancillería ${ }^{108}$ - hacia Sevilla de modo que el jueves 12 de junio pernoctaba en El Pedroso ${ }^{109}$, lugar donde a la mañana siguiente le llegaron cartas del maestre de Santiago en las que le decía que el almirante Egidio Bocanegra le había informado de que la flota de los reyes de Marruecos y Granada había pasado desde África y estaban ya en la orilla norte del Estrecho, concretamente en la desembocadura del río Guadalmesí ${ }^{110}$. A estas alturas, es posible que el maestre se hubiese recuperado ligeramente de su dolencia y hubiera llegado ya a Sevilla, como señala la Crónica ${ }^{111}$. Por ello, cuando el rey llegó a la ciudad del Guadalquivir, a mediodía del jueves día 13 de junio, el maestre le acompañó en su camino hacia Jerez, haciendo noche sucesivamente en la torre de los Herberos y en laguna de Tollos ${ }^{12}$ antes de llegar y Jerez, villa a la que el monarca y sus acompañantes llegaron el sábado 15 de junio ${ }^{113}$. Este rápido e inesperado desplazamiento del monarca había cogido por sorpresa a todos los que no estaban cerca del itinerario regio, así que como sus fuerzas eran de escasa entidad en aquellos momentos, en Jerez estuvo el rey don Alfonso esperando la llegada de la gente de los concejos de Córdoba y del obispado de Jaén para que, junto a las que él había conseguido movilizar en su camino, le acompañaran hasta las aguas del Estrecho con la finalidad de visitar a los vencedores de la batalla naval de Guadalmesí. A consecuencia de esta espera el viaje a la ensenada de Getares no se inició hasta finales del mes de junio, cuando ya hacía ocho días que había recibido carta del almirante Pedro de Moncada informándole que había derrotado

104. Ibidem.

105. Cañas Gálvez 2014, p. 382.

106. Así en Crónica, p. 338.

107. Cañas Gálvez, 2014 p. 382.

108. La cancillería real siguió emitiendo documentación desde Madrid hasta el día 7 de junio. No se conoce otro documento hasta el día 17 de dicho mes, ya extendido en Jerez.

109. Cañas Gálvez 2014, p. 382. Aquí se dice que el día 13 estaba en El Pedroso, pero eso fue al comenzar el día por haber pernoctado allí la noche anterior.

110. Así consta en Crónica, p. 339.

111. Ibidem.

112. En este último lugar situado muy cerca de la actual población de El Cuervo, hicieron noche el viernes 14 de junio. Aquí, según dice la Crónica, fue informado el rey de la victoria de la flota castellana en la batalla naval que comenzó en la desembocadura del río Guadalmesí el día anterior.

113. Cañas Gálvez 2014 p. 383 . Creemos que el Itinerario está ligeramente retrasado porque la laguna de Tollos está muy cerca de Jerez, y junto a dicha laguna acamparon la noche del viernes 14 de junio. 
a otra flotilla musulmana frente a Estepona y que se encontraba en Getares junto a la flota de Castilla ${ }^{114}$.

Según nos dice la Crónica, al rey de Castilla le acompañaban en aquella ocasión la gente de la Frontera, el arzobispo de Toledo y los maestres de las órdenes militares, por lo que entendemos que el maestre de Santiago fue a Getares y volvió de nuevo a Jerez unos días más tarde, para reemprender de nuevo el camino hacia el Estrecho el día 25 de julio ${ }^{115}$, con una hueste bastante más numerosa que la anterior entre la que se encontraban efectivos de la Orden de Santiago, con su maestre al frente como recoge la Crónica. De nuevo volvieron las fuerzas castellanas a la ensenada de Getares y, desde aquí, ya el día dos de agosto, emprendieron la marcha hacia Algeciras con la firme decisión de ponerle cerco.

El primer asentamiento de las fuerzas de la Orden de Santiago estuvo en las faldas de la colina en la que se ubicaba la torre de los Adalides, posando junto a las fuerzas del concejo de Sevilla, entre otras. Allí recibieron los castellanos el asalto de los algecireños y, a partir de aquí, comenzó una serie de operaciones y movimientos que llevaron a los santiaguistas a asentar finalmente en las proximidades del cementerio musulmán de Algeciras ${ }^{116}$. Para entonces, ya en el mes de septiembre de 1342, el maestre Alonso Méndez de Guzmán estaba gravemente enfermo y parece que falleció el día 14 de este mes, según leemos en un códice santiaguista $^{117}$. Por la Crónica sabemos de la disposición del rey para que los restos mortales del fallecido maestre fuesen llevados por mar hasta El Puerto de Santa María $^{118}$, aunque finalmente fue enterrado en el convento franciscano de san Clemente, en Sevilla ${ }^{119}$.

\section{Conclusiones}

Alonso Méndez de Guzmán fue nombrado maestre de la Orden de Santiago en la villa de Ocaña, a mediados del mes de agosto de 1338, como consecuencia directa de la voluntad del rey Alfonso XI. Después de permanecer el maestre en las posesiones santiaguistas situadas en La Mancha casi hasta finales de dicho año, llegó a tierras extremeñas a principios de 1339 con la intención de celebrar un Capítulo General en Mérida en el mes de marzo.

A partir de aquí, el nuevo maestre entra de lleno en la dinámica belicista que se vivió a lo largo de aquellos años contra granadinos y benimerines. En los sucesivos enfrentamientos que tuvo con los musulmanes demostró sobradamente su capacidad militar y su lealtad al rey de Castilla, motivo por el que éste lo dejó como máxima autoridad militar de la Frontera a finales de 1341 y comienzos de

\footnotetext{
114. Estos datos extraídos directamente de Crónica, pp. 341-342.

115. Ibidem, p. 343.

116. Ibídem, p. 345.

117. AHN. Códice 236-B, folio 129v.

118. Así en Crónica, p. 346.

119. Ayala Martínez 2003, p. 397.
} 
1342, según dice la Crónica. Así pudo ser, pero a pesar del encargo consta documentalmente que el maestre se alejó del entorno fronterizo a fines de aquel año y no volvió hasta los días finales del mes de mayo de 1342, por lo que entendemos que la función encomendada a la Orden pudo quedar en manos de los comendadores mayores de los reinos de Castilla y de León.

La Crónica señala además que Alonso Méndez de Guzmán cayó gravemente enfermo en la primavera del último año citado. Luego, ligeramente recuperado, acompañó a su rey desde Sevilla a Jerez y en los dos viajes que Alfonso XI hizo desde esta villa a la zona del Estrecho en los prolegómenos a la conquista de Algeciras. Sobre esta plaza estaba en el inicio del cerco, cuando su enfermedad lo llevó a la muerte en el mes de septiembre de 1342, siendo enterrado en el convento de san Clemente de Sevilla.

\section{APÉNDICE DOCUMENTAL}

Archivo Histórico Nacional. Sección de Sellos, carpeta 101, documento 2. Del pergamino colgaron en su día hasta 16 sellos, pero hoy sólo le quedan 7, la mayoría de ellos rotos e irreconocibles.

La Orden de Santiago cambia sus posesiones en Anna y Játiva por los lugares de Sagra e Cenet, pertenecientes estos últimos a don Pedro de Villanova, hijo del comendador mayor del reino de Aragón.

Sepan quantos esta carta vieren como nos don Alfonso Mendes por la gracia de Dios maestre de la orden de la cauallería de Santiago, con conosçimiento e con otorgamiento de don Gonzalo Yáñez prior de San Marcos de León, e de don Fernán Rodríguez prior de Uclés, e de don Sancho Sánchez, comendador mayor de Segura e de lo que nuestra orden tiene en el / regno de Castilla, e de don Fernan Rodríguez comendador mayor de Montemolín e de lo que nuestra orden tiene en el regno de León, e de don Gonzalo Gómez comendador del Corral, enmienda por don Vidal de Villanova, comendador mayor de Montalbán e de lo que nuestra orden tiene en el regno de Aragón, e de don Ruy Gómez de Manzanedo, comendador de Monte ${ }^{\beta}$ molín, e de don Álvar Núñez de Guzmán, e de don Men Vázquez comendador de Uclés, e don Martín Hurtado comendador de Ricote, e de Fernán Rodríguez comendador de Oreja, e de Fernán Ruys de Tauste comendador de Segura, e de Diego López de Caparroso comendador de Montiel, e de Johan López comendador de Destriana, enmienda por él Pero López su hermano, comendador de Mérida e Canena, e / de Diego Arias, comendador de Socovos, e de Alfonso Gomes comendador de Hornachos, que son los trece omes buenos de nuestra orden, e de los otros freyres omes buenos de nuestra orden que con nusco fueron juntados en el nuestro cabildo que fesimos en el real sobre Alcalá de Bençayde, sábado catorçe de julio desta era de esta carta, entendiendo que los lugares de Sagra e / de Çenet que son de vos, Pero de Villanova fijo del dicho don Vidal, que son asentados cerca de los lugares de Villajoyosa e de Orcheta, que son nuestros e de nuestra orden, los quales son poblados en lugar seguro en el término de Denia, e las rentas de los dichos lugares de Sagra e Çenet nos e la nuestra Orden podamos aver sin ningún embargo por la qual rasón $/{ }^{6}$ es muy provechoso a nos e la nuestra orden aver en uno. E porque nos, la dicha nuestra orden avemos en el lugar de Anna, que es asentado en el regno de Valençia 
en frontera de Castilla, en el qual lugar fasen muy gran daño almogavares e otras malas gentes e entendiendo, otrosí, que en los dichos lugares de Sagra e Çenet ay más / vasallos e pobladores que en el dicho lugar de Anna, por esta rasón e por otras que a nos e a nuestra orden mueve, otorgamos por nos e por los nuestros sucepsores de la dicha nuestra orden por esta presente carta para siempre valedera que cambiamos e permutamos convusco el dicho Pero de Villanova, fijo del dicho don Vidal de Villanova, comendador mayor de Montal / bán e de la nuestra orden en el reino de Aragón, presente, recibiere por firme e solepcial estipulación el dicho nuestro lugar de Anna, asentado en el regno de Valençia, con las casas e huertos de Xativa pertenecientes al dicho lugar de Anna, por los dichos vuestros lugares de Sagra e de Cenet, asentados en el dicho regno segunt que afronta el dicho lugar $/{ }^{9}$ de Anna con términos de la villa Xátiva e con término de la villa de Enguera e con término de Chella e de Boblayt e las dichas casas afrontan con casas de Pero Plumet e con la calle de Montidor e con casas de Martín Sánchez y el dicho huerto con la casa de los freyres de la Merced e camino en medio con la casa de la Almunia así que de aquí adelante por rasón / del presente cambio e procuraçión nos e los nuestros sucepsores en perpetuo ayades e tengades e poseades el dicho lugar de Anna e las dichas casas e huertos francos e libres con todos los omes e mujeres de qualquier ley e condiçión que sean allí moradores agora e de aquí adelante, e con todos sus términos e derechos e rentas o qualquier otro avenimiento y mejoramiento / segunt mejor y más provechosamente se pueda desir para que vos e los vuestros la puedan dar e vender e empeñar e enagenar e cambiar a todas voluntades de vos e de los vuestros para siempre fasederas segunt qual dicho lugar de Anna nos la dicha nuestra orden oy avemos e poseemos, prometiendo por nos e por los nuestros sucepsores de la dicha nuestra orden el dicho lugar $/ 12$ de Anna a vos el dicho Pero de Villanova e a los vuestros supcesores para siempre faser, tener, e aver e poseer con qualquier persona pacíficamente en sana pas, partiendo de nuestro poder e de nuestro señorío e de la dicha nuestra Orden el dicho lugar de Anna, e poniendo a vos el dicho Pero de Villanova en tenencia y en señorío del dicho lugar de Anna. E por / esta carta nos obligamos a vos el dicho don Pero de Villanova e a los vuestros para en todo tiempo los bienes de la dicha nuestra orden doquier que sean avidos e por aver. E nos con esta presente carta, la qual queremos que aya vos de epístola, mandamos a qualquier ome que en el dicho lugar de Anna moren o moraren, agora e de aquí adelante, tengan / a vos el dicho Pero de Villanova e a los vuestros por señores del dicho lugar e de sus términos e que respondan de aquí adelante a vos e a todos los vuestros con todas las rentas e derechos e qualesquier avenimiento en el dicho lugar de Anna e de sus términos, salvo el derecho del dicho don Vidal, comendador mayor de suso dicho, el qual a por su vida el dicho lugar $/{ }^{15}$ de Anna. E porque todo lo que dicho es en esta carta sea firme y valedero para en todo tiempo, mandamos la sellar con nuestro sello e con los sellos de los dichos priores e de los comendadores omes buenos de nuestra orden. E yo, el dicho Pero de Villanova reçibo de vos el dicho señor maestre don Alfonso Mendes, e de los dichos priores, e de los comendadores e de los otros freyres e omes buenos sobredichos de la / vuestra orden el cambio del dicho lugar de Anna. Otorgo que cambio con vos el dicho señor maestre e con vuestra orden para todos los tiempos los dichos lugares de Sagra e Çenet, asentados en el término de Denia, por el dicho lugar de Anna segunt que el dicho lugar de Sagra afronta con el término de la villa de Pego, e con el tér / mino del lugar de Rahal, e con el término del lugar de Tormes, e el dicho lugar afronta con el término del lugar de Negra e con la sierra de Segarra, asi que de aquí adelante vos el dicho señor maestre e los vuestros sucepsores en la dicha vuestra Orden en perpetuo ayades e ${ }^{18}$ tengades e poseades los dichos lugares de Sagra e Cenet, francos e libres, con todos los omes e mujeres de qualquier condiçion que sean, que agora y moren o moraren de aqui adelante con todos sus terminos e derechos e rentas e qualesquier otros avenimientos o mejoramientos, segunt mejor e mas 
provechosamente lo podíades aver vos e los / vuestros sucepsores en la dicha orden e que puedan dar e vender e empeñar e cambiar e enagenar a todas vuestras voluntades e de la dicha vuestra orden para siempre jamás segunt que yo los dichos lugares hy los poseo, e prometo por mi e por todos los míos a vos el dicho señor maestre, a los vuestros sucepsores e a la dicha vuestra orden los dichos lugares de / Sagra e Çenet, faser e tener e poseer para siempre con qualesquier persona pacíficamente en sana paz, e para esto me obligo todos los mis bienes que agora he o abre, de aquí adelante por doquier que yo aya. E porque esto sea firme e duradero para en todo tiempo, yo el dicho Pero de Villanova escribí en ${ }^{21}$ esta carta mi nombre y puse en ella mi sello, e rogue a Jayme Çatistevan, vesino de Xativa, e a Bernal Soler, notario de Valencia, que fuistes de esto testigo pusiesen allí sus nombres. E nos el dicho maestre don Alfonso Mendes e los dichos priores, comendadores e los otros freyres omes buenos de nuestra Orden prometemos que al / primero Cabildo general que fisiéremos que vos demos nuestras cartas selladas con nuestro sello e con el sello del Cabildo de dicho cambio e donaçión que fasemos. Dada en el real de sobre Alcalá de Bençayde, catorçe días de julio era de mil e tresientos e setenta e nueve años.

\section{BiBLIOGRAFÍA CITADA}

Fuentes manuscritas

AHN. Códice 314-B.

AHN. Códice 236-B.

Fernández de Oviedo, Gonzalo, Elogios y relaciones de personas y linajes. Biblioteca Capitular de Sevilla. Folio 50r.

Fuentes publicadas

Argote de Molina, Gonzalo (1957), Nobleza del Andalucía (1588). Facsímil del Instituto de Estudios Giennenses. Jaén.

De Orozco, Pedro; Juan De la Parra, Juan (1978), [Primera] Historia de la Orden de Santiago. Manuscrito de la RAH. Introducción trascripción, notas y apéndice del Marqués de Siete Iglesia. Publica la Institución Pedro de Valencia de la Diputación de Badajoz. Badajoz.

Ortiz de Zúñiga, Diego (1795), Anales eclesiásticos y seculares de la muy noble y muy leal ciudad de Sevilla, libro V. Imprenta Real. Madrid.

Rades y Andrada, Francisco (1980), Crónica de las tres órdenes, de Santiago, Calatrava y Alcántara. Toledo (1572). Facsímil de Ediciones El Albir. S. A. Barcelona.

Yáñez, Rodrigo (1966), “Poema de Alfonso el Onceno rey de Castilla”. En Poetas anteriores al siglo XV. Biblioteca de Autores Españoles, volumen 57. Ediciones Atlas. Madrid.

Corónica del muy alto et muy católico rey don Alfonso el onceno (1953). Volumen I de las Crónicas de los reyes de Castilla. Biblioteca de Autores Españoles. Vol. LXVI. Ediciones Atlas. Madrid. 
Documentos de los siglos XIV y XV. Señoríos de la Orden de Santiago (1991). En Colección de Documentos para la Historia del Reino de Murcia, XVII. Edición de Miguel Rodríguez Llopis. Murcia.

Gran Crónica de Alfonso XI (1976). Preparada por Diego Catalán en el Seminario Menéndez Pidal. Editorial Gredos. Madrid.

Memorial del duque de Medinaceli a Felipe V (1707). Escrito por don Luis de Salazar, compuesto y transcrito por Juan Luis Pérez Arribas.

Bibliografía

Arias Guillén, Fernando (2012), Guerra y fortalecimiento del poder regio en Castilla. El reinado de Alfonso XI (1312-1350). Ministerio de Defensa. CESIC. Madrid.

Ayala Martínez, Carlos de (2003), Las órdenes militares hispánicas en la Edad Media (siglos XII-XV). Marcial Pons Historia. Latorre Literaria. Madrid.

Cañas Gálvez, Francisco de Paula (2014), Itinerario de Alfonso XI de Castilla. Espacio, poder y corte (1325-1350). La Ergástula ediciones. Madrid.

García Fernández, Manuel (1991), "Doña Leonor de Guzmán y Andalucía. Formación, consolidación y repoblación de su patrimonio señorial (1332-1344)". Actas del II Congreso de Historia de Andalucía. Junta de Andalucía y Caja Sur. Córdoba, pp. 119-128.

Gómez Redondo, Fernando (1999), Historia de la prosa medieval castellana, vol. II. Editorial Cátedra. Madrid.

González Crespo, Esther (1988), "El afianzamiento económico y social de los hijos de Leonor de Guzmán”. Anuario de Estudios Medievales, 18. Barcelona, pp. 289-303.

Ladero Quesada, Miguel Ángel (1988), “Los señores de Gibraleón”. En, Los señores de Andalucía. Universidad de Cádiz. Cádiz.

Lomax, Derek W (1965), La Orden de Santiago (1170-1275). CSIC. Madrid.

López Fernández, Manuel (2005a.), “Aproximación histórico-jurídica al Fuero de Llerena”. Actas de las VI Jornadas de Historia en Llerena. Llerena.

López Fernández, Manuel (2005b), "El itinerario del ejército castellano para descercar Gibraltar en 1333”. Espacio Tiempo y Forma, 18. Facultad de Geografía en Historia de la UNED. Madrid.

López Fernández, Manuel (2007), "Del desastre de Getares a la victoria del Salado. La crítica situación de la zona del Estrecho en 1340." Espacio, Tiempo y Forma, 20. Facultad de Geografía e Historia de la UNED. Madrid.

López Fernández, Manuel (2008), "Unos apuntes sobre el botín del Salado”. Aljaranda, 71. Tarifa.

López Fernández, Manuel (2015), “Aproximación al Fuero de Fuente de Cantos". Actas de la XVI Jornada de Historia de Fuente de Cantos. Fuente de Cantos, Badajoz.

López Fernández, Manuel (2017), “La defensa de Tarifa en 1340. Aproximación a la figura de su alcaide". Aljaranda. Tarifa, en presa. 
Porras Arboledas, Pedro Andrés (1997), La Orden de Santiago en el siglo XV. La provincia de Castilla. Dykinson. Caja Provincial de Ahorros de Jaén. Jaén.

Porras Arboledas, Pedro Andrés (2012), "Sobre el fuero extenso de Mérida". Cuadernos de Historia del Derecho, 19. Madrid.

Porras Arboledas, Pedro Andrés (2014), "Sobre el fuero extenso de Segura de la Sierra”. Revista de la CECEL, 14. Madrid, pp. 14 y 20.

Rivera Garretas, Milagro (1985), La encomienda, el priorato y la villa de Uclés en la Edad Media (1174-1310). CSIC. Madrid-Barcelona.

Sáez, Emilio (1953), Los Fueros de Sepúlveda. Segovia.

Sánchez Arcilla, José (1995), Alfonso XI, 1312-1350. Editorial La Olmeda, Palencia.

Sánchez Saus, Rafael (1989), Caballería y linaje en la Sevilla medieval. Diputación Provincial de Sevilla y Universidad de Cádiz. Sevilla.

Sánchez Saus, Rafael (1991), Linajes sevillanos medievales. Ediciones Guadalquivir, Sevilla.

VV. AA. (2012), El siglo XIV en primera persona. Alfonso XI rey de Castilla y León. Sevilla.

Fecha de recepción del artículo: 13 de enero de 2017

Fecha de aceptación y versión final: 14 de marzo de 2017 